\title{
The purposes of cultural supervision
}

\section{Anaru Eketone}

Anaru Eketone is from Ngäti Maniapoto and Waikato and is a Senior Lecturer in Social Work at the University of Otago. Prior to that, he worked for ten years as a youth worker in South Auckland and six years as a health promotion adviser in Dunedin. He is married to Margaret and together they have two adult children.

(This article was originally accepted for publication for Te Komako, 2009.)

\section{Introduction}

If you are working in the social services sector, over 40 and Mäori, chances are that you will have been asked to provide cultural supervision for a younger Mäori worker. However, when you ask what do they mean by cultural supervision, after a slightly panicked look, you can get a variety of different answers. They all know that it is supposed to be done, that it is considered important, in fact some are required by their employers or contracts to have it, but until very recently few seem to know what they actually wanted. This article reports on a brief research project as part of a Masters in Social Welfare programme that interviewed Mäori social workers and Mäori and Päkehä social work managers about their expectations and experiences of cultural supervision. The participants were asked four questions about the purpose of cultural supervision, who should get cultural supervision, the qualities of a cultural supervisor and problems they had encountered in cultural supervision.

Four different types of cultural supervision are identified and a framework is suggested for what is referred to as 'culturally effective supervision'.

\section{What is cultural supervision?}

Outside of New Zealand, the term cultural supervision usually refers to cross-cultural supervision, i.e. the supervision of supervisees by a person of another culture. Internationally there are three prevailing perspectives. The first perspective is defined as a multi-cultural approach where Ladyshewsky (1996) looked at some of the issues that arose for white Australian supervisors when working with East Asian supervisees. It was found that cultural assumptions interfered with their ability to communicate; for instance, supervisees who did not exhibit the right independence and individualisation were seen as less able than western supervisees, while a limitation of vocabulary led to perceived indecision and perceived lack of an appropriate manner. To overcome some of these misunderstandings, Ladyshewsky favoured a multicultural approach to cross-cultural supervision based on supervisors learning a little about different East Asian cultures and values.

The second perspective encourages supervisors to look primarily at themselves rather than the culture of the supervisee. Peterson (1991) performed a study on racial/ethnic attitudes between therapists and their supervisors in the United States. He believed that a supervisor involved in cross-cultural supervision could ensure good practice, not by looking at the culture of the supervisee, but by constantly looking at their own beliefs and 
stereotypes to reflect on whether they were imposing their own cultural expectations on the supervisee.

The third perspective encouraged supervisor and supervisee to identify similarities between cultures focusing on personal agency and potential opportunities rather than on problems. Edwards and Chen (2002) proposed the 'Wu-wei' supervision method for crosscultural supervision, incorporating a 'post-modern view of human systems interaction' that is 'language-generated and meaning-generated where individuals are seen as responsive and responsible to others in their social context' (Edwards and Chen, 2002, pp. 5-6). Their method seeks to establish non-hierarchical relationships that provide supervision that includes a 'non-pathological frame of reference, and maintains a 'not-knowing' and active/non-active stance.' Wu-wei seeks to identify areas of similarity between two systems (e.g. cultures) to work together and seek areas of interconnectedness (Edwards \& Chen, 2002).

While three cross-cultural supervision perspectives have been important internationally, in New Zealand it is a recent development with little written about it. If mentioned, often it will refer to Päkehä supervisors supervising Päkehä, to ensure they are responsive to clients who are of a different culture. Chapman (2002) speaks of cross-cultural supervision as usually referring to an ability of Päkehä social workers to work with Mäori and is therefore focused on a knowledge of tikanga Mäori. However, when working with refugees his organisation needed a broader way of working as social workers couldn't be expected to learn all the customs of everyone they encountered. Chapman therefore trained his supervisees in 'the process of engaging with clients and teaching the methods of gathering cultural specific information from the clients about their internalised world' (Chapman, 2002, pp. 151).

What has been more common in the New Zealand context, is a focus on the need for culturally appropriate supervision. In his study of supervision in the community probation service, O’Donoghue (2000) identified four functions of New Zealand supervision:

- the maintenance of boundaries and ethics

- protection from unsafe practices

- a form of quality assurance

- providing reassurance to clients that the people seeing them were competent and accountable.

Although he does not mention cultural supervision directly, he did identify that traditional supervisory approaches were not suitable for all social workers.

Social workers in Aotearoa New Zealand seem mainly to have only experience of indirect methods of supervision such as the individual supervision session where they report or discuss their work and work related matters. This generalised experience of one form of supervision, which utilises indirect methods, is problematic because it is not responsive to the needs, culture and the work issues of all supervisees (O’Donoghue, 2000, pp. 9).

Pacific social workers are one group who have sought to have their needs, culture and values upheld in supervision. Auatagavaia (2000) is critical of supervision by Palagi of Pacific peoples but argues that an inclusive model of cross-cultural supervision can come about by the creation of a relationship based on trust and dialogue. However, she believes the most appropriate form of supervision for a Pacific Island's social worker is by a Pacific 
Island's supervisor. In this context she and other pacific supervisors and supervisees see supervision as;

A sharing process between Pacific Islands supervisor and supervisee, facilitated by the supervisor to provide healing, encouragement and challenges to the supervisee to enhance the personal, cultural and professional self (Auatagavaia, 2000, pp. 4-7).

To facilitate this, she has designed a model where the function of Pacific people's supervision is to deal with professional, cultural and personal issues.

A number of Mäori writers have also called for culturally appropriate supervision that meets the cultural needs of Mäori social workers. Bradley, Jacob \& Bradley (1999, p. 3) stated that 'the vital imperatives of Mäori supervision are drawn from a Mäori world view.' He says that Mäori have a set of key cultural values and principles such as: aroha, wairua, whanaungatanga, mana motuhake, te reo, tikanga and kawa that underpins Mäori practice methods and therefore workers need supervisors who are conversant and confident with these values.

Disciplines other than social work have also sought cultural supervision of their professional Mäori workers. McKinney (2006) surveyed 24 Mäori doctors about their experiences and expectations of cultural supervision. The respondents believed that cultural supervision had two main purposes. The first was about ensuring they behaved in an appropriate way for the safety of patients and the second was the support of Mäori doctors in dealing with mainstream institutions. All believed that supervisors should have in-depth cultural knowledge as well as an understanding of the context, in this case, the medical/health system as well as an understanding of how to apply the culture in that context especially through tikanga and te reo. McKinney was concerned about the number of doctors who found themselves in 'culturally complex' situations or described themselves as 'not culturally confident' and so cultural supervision was seen as a way of becoming culturally competent. This was particularly important as all participants felt that 'cultural and clinical competence were of equal importance' (McKinney, 2006, p. 304).

Recently there has been advocacy for what has become known as a Kaupapa Mäori approach to cultural supervision. Tapiata-Walsh and Webster (2004) advocate for a Kaupapa Mäori supervisory approach to ensure the safety, accountability and professionalism of kaimahi Mäori that also provides learning opportunities and ensures that social workers are accountable, ethical and professional in their practice. Another advocate for Kaupapa Mäori supervision took it further and defines Kaupapa Mäori supervision as;

... an agreed supervision relationship by Mäori for Mäori with the purpose of enabling the supervisee to achieve safe and accountable professional practice, cultural development and self-care according to the philosophy, principles and practices derived from a Mäori worldview (Eruera 2005, p. 61).

Eruera also outlines a number of key principles and concepts that underpin Kaupapa Mäori supervision based around Mäori knowledge, a Mäori worldview and a number of Mäori processes, concepts and roles such as whakapapa, Kaikörero, tuakana-teina, and whanaungatanga. 
Others have drawn up frameworks and models for supervisors to follow using many of the aforementioned Mäori cultural values. In 1997 and 1999 Ema Dreadon proposed a kaupapa Mäori model of supervision called 'Äwhiowhio' that followed the traditional stages of the powhiri process and parallels them as steps in the supervision process of Mäori. She also outlined a model of appropriate supervision practice, a three-dimensional approach to supervising Mäori that included an organisational supervisor who deals with the administration and organisational tasks, a tangata whenua supervisor who deals with appropriate tangata whenua practice and a kuia or kaumätua who shares their wisdom under their spiritual korowai. While agencies may baulk at having to bear the costs of three different supervisors, this approach came as a response to the lack of available Mäori social worker supervisors who understand both the nature and practice of social work and the values and processes of Mäori society.

The Department of Corrections, recognising the lack of qualified cultural supervisors in their own ranks produced guidelines for external Mäori supervisors and attempted to define criteria for what they want in a cultural supervisor. An un-attributed copy of 'Guidelines for Appointment of Cultural Professional Supervisors' was obtained from the Department of Community Correction's that outlined the following when appointing cultural supervisors. They:

- will have support and approval from local iwi and be recognised by their iwi as having an expertise and/or depth of knowledge in relation to cultural practices.

- are able to demonstrate respect and empathy towards the department's values, goals and purposes.

- will have an awareness of and sensitivity towards the needs of individuals from different cultures

- will have cognisance of the supervisee's cultural background and the cultural context of the department (Community Corrections, obtained 2002).

The Department of Corrections also contributed to one of the clearest explanations of the purpose of this form of cultural supervision which Walsh-Tapiata and Webster (2004) adapted from a departmental draft policy in 2001. They said that the purpose of cultural supervision was to:

- build a worker's knowledge of Mäori cultural values,

- provide a supportive context for kaimahi to manage complex cultural issues,

- ensure safe practice and culturally appropriate behaviour,

- clarify roles, responsibilities and accountabilities,

- define the parameters for cultural supervision as distinct from training and development or professional supervision,

- promote professional development by developing skills, knowledge, confidence and competence in understanding Mäori attitudes and behaviours in an area of practice,

- provide opportunities for the worker to appraise their responsiveness to Mäori within their practice,

- support kaimahi learning by linking practice to cultural knowledge.

So far we have seen how there is a wide range of views and definitions from international and New Zealand perspectives of what cultural supervision is. The following section asks practitioners themselves about their understanding and expectations of cultural supervision. 


\section{Methodology}

This study looked at cultural supervision from three different perspectives with eight people interviewed. Those interviewed were three Mäori social workers within government organisations, two managers (one Mäori and one Päkehä) of not-for-profit Mäori social service agencies and there were three Päkehä managers of mainstream services who have responsibilities for Mäori workers on their team (two were from government organisations and the other runs a not-for-profit agency). All participants were well known to the researcher, either being past colleagues or having served on the same social service sector committees. All were over the age of 40 and had at least five years' practice experience, with five having over 15 years' experience in the social service sector. While this is admittedly a very small group and therefore limited in its ability to generalise, it does unveil some interesting perspectives that others may want to pursue in greater depth.

The interviews were done by using a semi-structured interview process using a semistandardised and open technique (Sarantakos, 1993, p. 179, 187) using the four following base questions: What is the purpose of cultural supervision? Who should get cultural supervision? What are the qualities of a cultural supervisor?, and What problems have you encountered in cultural supervision?

\section{Results}

\section{What is the purpose of cultural supervision?}

The Mäori social workers said cultural supervision involved someone questioning the cultural appropriateness of your practice and service delivery, looking at how you could have done things better. It is a time when someone is holding you accountable for cultural safety and it is a place to discuss Mäori theories and methodologies. They said that it is somewhere where you can get cultural advice for your own protection, i.e. safety for you, around things Mäori. A place where you are being encouraged and someone is looking out for you and questioning whether your needs are being met, a place where what you share is heard on a deeper level, from the wairua. One worker said that it is critical that you are able to share with someone who is not struggling to understand where you are coming from. They also said that they wanted advice and support with strategies to change their organisation from the inside as well as a place to 'spit the dummy' over frustrations with their agency and their work-mates.

The Mäori managers said that they saw cultural supervision as a place to ensure the safety of the workers and the clients. A place where staff develop their practice to work more appropriately with clients so that it is safe for whanau and safe for individuals. It is also a place where they present their practice, where workers are challenged over their beliefs, ideas and practice, asked the difficult questions and offered another perspective. They saw it as a place where workers could discuss their boundaries and roles, with a focus on gender, their iwi and their status in the Mäori community. One felt that cultural supervision comes from a response to the Treaty of Waitangi, needs clear understanding of the purposes of cultural supervision and that there needs to be a clear relationship, with a clear contract and a financial commitment. One hadn't liked the way cultural supervision had been used by agencies to give the perception that the agency was meeting their requirements under the Treaty of Waitangi so they can say 'look we've done it' but without establishing formal relationships with iwi. 
The Päkehä managers identified three types of supervision: administrative, professional and cultural. They had a list of what they expected cultural supervision to do that fell into three categories. The first related to the work done with the client - that the client was being treated in an appropriate safe manner, and that issues about the client were being spoken to by someone who understood the cultural relevance and meanings.

The second category of expectations was to do with the support and management of the worker. It was seen as a mediation process, where they can vent off frustrations in a safe place, a place to prevent conflicts of being Mäori and working with Mäori. It was seen as an opportunity to talk to an outsider about the organisation, separate from social work requirements and receiving cultural support as well as support in the learning of new approaches

The third category of expectations for cultural supervision was to help the agency deal with internal conflict in the agency, including liaison over issues of racism within the organisation. They wanted cultural supervision to uphold the organisation's values and deal with conflict over allegiance to the organisation. One felt that some Mäori workers are anti-agency and if they are 'halfway political' then it causes tension within the organisation.

One agency provided cultural supervision on an 'as needed basis' the other two saw it as an entitlement. One Päkehä manager liked the idea of cultural supervision because they needed to know that the worker was 'doing their job'. One also felt that a number of Mäori workers were starting on their journey as a Mäori and the agency looked to cultural supervision to support them in that journey

The manager of the not-for-profit agency also used cultural supervisors for non-Mäori staff and of the seven agencies represented was the only one who did so. They used it to help Päkehä 'grapple' with particular issues. They felt that Päkehä 'don't know what they don't know', and need cultural supervision to expose that so that it can be dealt with.

\section{Who should get cultural supervision?}

The Mäori social workers said that firstly cultural supervision should be available to anyone working with Mäori clients. They said that if a Päkehä worker is working with Mäori clients there must be something to make them accountable to make sure what they are doing is appropriate.

The Mäori managers also said that anyone who wants cultural supervision should be able to get it, with a priority for new social workers so that they learn good practice. They too, saw cultural supervision as not only being important for Mäori, but anyone working cross-culturally and as essential for people working in the health and justice fields.

The Päkehä managers were in agreement that it should be available for anyone who wants it. One saw cultural supervision as an entitlement not just another add-on. Their agency believed it was their responsibility to offer it to Mäori staff but it was not offered to Päkehä staff. Another thought 'cultural type' supervision should be open to staff in other ways as well, e.g. a women's supervisor to discuss women's issues. 


\section{What are the qualities of a cultural supervisor?}

All three of the Mäori social workers said that the main requirement was someone who came with a strong knowledge of tikanga, primarily to keep the workers from making mistakes so that they were working in a culturally safe way for themselves, the client and their whänau. They would prefer someone with a good academic social work knowledge but in the end tikanga was more important. One wanted a supervisor with the same historical background as they had, i.e. that they had lived in the 'Mäori world', so that they wouldn't have to keep explaining themselves about the way they thought and acted. Another wanted a cultural supervisor who knew a lot about the local people, tikanga, kawa etc., with a knowledge of the political workings of the region to keep them up to date with what is going on.

Mäori managers wanted someone who was skilled in tikanga and social work practice with a long-standing reputation and credibility in the community, someone whose practice was based on life, not what they read in a book. One wanted someone who could work multiculturally as well as with Mäori.

Päkehä managers wanted someone with strong networks, maturity, credibility and knowledge of the local iwi. A background in working with people was considered very important, although not necessarily social work. One manager had been frustrated in their efforts to get what they considered to be the right people for the agency, some who had been contracted had not been considered useful. They had had particular problems with cultural supervisors who were anti-establishment and/or anti-agency. There was also trouble finding someone acceptable to iwi who also had a knowledge of the organisation and its issues. One manager wanted someone also able to engage with Päkehä staff to deal with cultural questions and issues.

\section{What problems have you encountered with cultural supervision?}

A major problem that the Mäori social workers had identified with cultural supervision was primarily their agency's attitude to it. One felt that they were in a double bind, where they were accountable to a Tauiwi system that told them how to be accountable to Mäori. There was a general feeling that cultural supervision was not valued, that their organisations had little understanding that the workers have to live and exist in the Mäori community and that support was needed to do their job properly.

The Mäori managers did not seem to have problems around getting good cultural supervision for their agency but they did have concerns about how Päkehä/mainstream agencies were using it. They saw cultural supervision being used as a way for agencies to sort out their own 'screw-ups' used as a 'clean-up tool' instead of being used to prevent problems. There was also some concern over the use of kaumätua or kuia steeped in tikanga but who had little understanding of the discipline they were overseeing. One also felt that there was an inequity of payments where Päkehä supervisors would be paid market rates but a kaumätua would only get a $\$ 20$ koha.

Päkehä managers also identified a number of problems. One was the suspicion that sometimes the people they got as cultural supervisors weren't confident or competent to supervise. It was also difficult finding the right supervisor when their worker was someone who had high standing in their community. There was a concern about the expectation of Mäori having to educate their colleagues and the fact that cultural supervision was often ir- 
regular. One found difficulties and conflict over organisational values such as confidentiality and sometimes the supervisor was adding to the problem. The organisation wanted cultural supervisors, but not ones who were too radical. They wanted someone who would help Mäori work in a way that didn't cause the agency difficulties. The manager who arranged cultural supervision for Päkehä workers stated that one of their needs was the creation of an environment where people had permission to make mistakes, to bring their not-knowing and to explore issues in a no-holds barred way.

\section{Summary}

All participants saw the primary role of cultural supervision as ensuring the safety of staff and clients. The Mäori workers in particular were quite strong on what they wanted from supervision, they were terrified of getting tikanga wrong and were after someone who would oversee their practice. They were also strong on the opinion that Päkehä who were working with Mäori need cultural supervision to ensure the safety of their practice. All Mäori also wanted someone with credibility in the Mäori community to go with their knowledge of tikanga.

The perspective with the greatest divergence in opinion was identifying the problems with cultural supervision. Mäori social workers and managers said the main problems were with what were considered mainstream agencies, their attitude and their misuse of cultural supervision. Päkehä managers' concerns were mostly to do with doubts over the cultural supervisors themselves with questions over their competence and where their allegiance lay. Conversely, the Mäori managers interviewed had few problems in finding appropriate people to provide cultural supervision

\section{Discussion}

From the literature and the research, four separate types of cultural supervision have been identified, they are:

1. Cross-cultural supervision where supervision takes place between two people of differing cultures.

2. Culturally appropriate supervision or generic cultural supervision where supervision takes place with workers working with clients from a different culture than themselves.

3. Culturally competent supervision where supervision takes place between people of the same culture (in this case Mäori), using that culture's world view, models and frameworks in a manner that is consistent with the context. It examines the approach of the worker in a way that is itself culturally appropriate.

4. Culturally effective supervision where the purpose is to support, educate and to protect the worker, looking at the environment and their practice so that they in turn work in an appropriate and safe way with the client.

The difference between culturally competent and culturally effective supervision may not be immediately obvious. From a personal viewpoint I think I can best describe the difference by saying that I believe that I could personally provide culturally competent supervision today, but that I am about 10-15 years away from being able to provide culturally effective supervision. It is also important to distinguish these terms from what others may call 'kaupapa Mäori 
supervision'. Both 'culturally competent supervision' and 'culturally effective supervision' can be forms of 'Kaupapa Mäori supervision' as both can use kaupapa Mäori methodologies. In other words, you can use a kaupapa Mäori approach in culturally competent supervision, just as you can in culturally effective supervision; the underpinning worldviews are identical, it is the functions and their objectives in supervision that are different.

In western society there are three functions of social work supervision most commonly mentioned in the literature - they are administration, education and support (Kane, 2001). The major difference between the functions of Mäori cultural supervision and western supervision is that in culturally effective supervision there is less of an emphasis on the administrative function and a greater emphasis on protection, i.e. a spiritual and cultural covering over the worker, the agency and the work with the client.

Taking these three functions of culturally effective supervision of education, support and protection, it is possible to suggest a framework describing the functions of culturally effective supervision for Mäori. The three supervision functions with their associated roles are;

\section{Education.}

- Personal development, work-force development, continuation of lifelong learning, preparing for future roles in the Mäori community.

- Developing practice.

- Tikanga Mäori including values, worldview and practices appropriate and applicable in social work.

- The rights, roles, expectations and obligations in the Mäori community for that person at that time (i.e. taking into account gender, age, status, knowledge of 'te reo me ngä tikanga').

- Boundaries and accountabilities.

- The role and impact of the wairua dimension in practice.

2. Support.

- Professional, i.e. dealing with clients.

- Personal and emotional support, i.e. your personal life, personal issues etc.

- Support in the agency, i.e. dealing with colleagues, institutional racism, communication between agency and worker in a language both understand.

- Support in the Mäori community, because the worker returns there when they walk out the door of their office.

- Wairua dimension, i.e. dealing with client issues where the worker finds themselves out of their depth.

3. Protection.

- Ensure they are working in a culturally safe way for the protection of clients.

- Working in a culturally safe environment and in a culturally safe way for the safety of the supervisee.

- Provide protection in the community by ensuring tikanga is adhered to, mana is acknowledged and enhanced, and, tapu is protected.

- Accountability for practice (including boundaries).

- Dealing with issues of violation of tapu and tikanga.

- Dealing with the wairua dimension. 
Cultural supervision is an important part of Mäori social work practice. Mäori social work is no longer the primary domain of pakeke looking for ways to apply the skills, insights and experience that they had obtained through involvement with their families, marae and communities. There is an increasing number of younger urban Mäori, unsure of tikanga, but with a heart to support the advancement of our people one whänau at a time and they are in need of guidance and support. In her PhD thesis, Awhina English (2012) has identified a growing demarcation between those who call themselves 'Mäori social workers' and those who call themselves 'social workers who are Mäori'. It is the younger urban social workers who are more likely to identify themselves as social workers who are Mäori, and while they have the freedom to choose which professional identity they are most confident with, it does reveal a greater need for competent mentors and cultural supervisors. In this study the few Mäori managers interviewed had little trouble finding appropriate cultural supervisors, but, Päkehä managers with fewer contacts and a lesser understanding about the nature of cultural supervision, had a greater struggle ensuring their Mäori workers have appropriate cultural supervision.

In conclusion, all four of the identified types of cultural supervision have application for Mäori social workers and their clients. However, it is proposed that 'culturally effective supervision' with its three purposes of the education and support of Mäori workers with a focus on the cultural protection and safety of staff and their clients, is the form that most closely aligns to what Mäori practitioners themselves are looking for. The difficulty that mainstream employers have of finding appropriate cultural supervisors coupled with a lack of confidence in using Mäori approaches in social work by many young Mäori social workers, must have implications for mainstream service providers and the services delivered for clients. If there is an increasing pressure and expectation by agencies, colleagues and clients for these younger Mäori workers to work using Kaupapa Mäori-informed processes, the need then for appropriate cultural supervision that enables Mäori social workers to work confidently and safely will continue to grow.

\section{References}

Autagavaia, M. (2000). A Tangata Pasifica supervision process: Authenticating difference. In L. Beddoe \& J. Worrell (Eds.). From rhetoric to reality. Keynote address and selected papers. Conference proceedings. Auckland.

Bradley, J., Jacob, E., \& Bradley, R. (1999). Reflections on culturally safe supervision, or why Bill Gates makes more money than we do. Te Komako, Social Work Review, III, XI, (4), pp. 3-6.

Chapman, A. (2002). Social work with clients who are refugees or migrants. In R. Truell, L. Nowland. Reflections on current practice in social work. New Zealand: Dunmore Press.

Community Corrections. (No Date). Guidelines for appointment of cultural professional supervisors.

Dreardon, E. (1997). Matua whakapai tou marae, ka whakapai ai I te marae o te tangata: First set in order your own marae before you clean another. Te Komako, Social Work Review, 8, p. 1.

Edwards, J.K., \& Chen, M. (2002). Strength-based supervision: Frameworks, current practice and future directions: A wu-wei method. The Family Journal (In press). Retrieved from www.neiu.edu/ jkedward/wu-wei.

English, A. (2012). Mäori social workers: Experiences within social service organisations. A thesis submitted for the degree of Doctor of Philosophy, University of Otago.

Eruera, M. (2005). He Korero Korari, Supervision conference 2004 -Weaving together the strands of supervision. Auckland University: Faculty of Education.

Kane, R. (2001). Supervision in New Zealand social work. In M. Connolly (Ed.). New Zealand social work: Contexts and practice, pp. 291-303. Auckland: Oxford University Press.

Ladyshewsky, R. (1996). Cross cultural clinical supervision/education: The SE Asian experience. In J. Abbott \& L. Wilkcoxson (Eds.). Teaching and learning within and across disciplines, 99-104. Proceeding's of the 5th Annual Teaching Learning Forum, Murdoch University, February 1996. Perth: Murdoch University.

McKinney, J. (2006). A Mäori medical model of cultural supervision. NZFP, 33(5), p. 301-304. 
O'Donoghue, K. (2000). The future of social work supervision within Aotearoa/New Zealand. A paper presented at the National Supervision Conference, Supervision: From Rhetoric to Reality. July 2000. Auckland: The Auckland College of Education.

Peterson, F. (1991). Issues of race and ethnicity in supervision: Emphasising who you are, not what you know. Winter 1986, No. 1, The Hayworth Press.

Sarantakos, S. (1993). Social research. South Melbourne: Macmillan Education Australia Pty Ltd.

Walsh-Tapiata, W., \& Webster, J. (2004). Do you have a supervision plan? Te Komako Social Work Review, VII, pp. 15-19.

Webber-Dreadon, E. (1999). He taonga mo o matou tipuna (A gift handed down by our ancestors): An indigenous approach to social work supervision. Te Komako, Social Work Review, III, XI(4), pp. 7-11.

Wong, P., \& Wong, L. (No date). Multicultural supervision questionnaires, retrieved from www.twu.ca/cpsy/survey/multi. 